\section{Oral sedation for dental treatment in young children in a hospital setting}

\author{
L. Lourenço-Matharu ${ }^{1}$ and G. J. Roberts ${ }^{2}$
}

IN BRIEF

- Provides information on the safety of oral sedation in clinical paediatric dentistry.

- Provides information on the efficacy of oral sedation when providing care to children.

- Demonstrates the broad range of procedures in young children who would otherwise have had general anaesthesia.

\begin{abstract}
Introduction Conscious sedation for young children is a rapidly developing area of clinical activity. Many studies have shown positive results using oral midazolam on children. These case series investigated oral midazolam conscious sedation as an alternative to general anaesthesia in a clinical service setting. Objective The purpose of this work was to determine the safety and efficacy of oral midazolam for conscious sedation in children undergoing dental treatment. Methods Patients were selected by colleagues for treatment under oral sedation. The main general criteria were weight below 36 kilos and ASA I, II, or III. Midazolam $0.5 \mathrm{mg} / \mathrm{kg}$ was administered orally. A pulse oximeter was applied to a finger to monitor vital signs and the Houpt scale was used to assess behaviour. Results A total of 510 children aged between 13 months and 11 years were included. The behaviour of 379 (74\%) was excellent or very good. The pulse rate and peripheral oxygenation were within the normal range for all patients. The main adverse effects were diplopia and post-sedation dysphoria. Conclusions Oral midazolam is a safe and effective method of sedation although some children were agitated and distressed either during or after treatment. Parents need to be warned about this.
\end{abstract}

\section{INTRODUCTION}

Pain control during the provision of dental treatment for children continues to be a challenge. Oxygen nitrous oxide inhalation sedation (IS) has been used increasingly over the last 25 years. ${ }^{1}$ The main limitation is that the technique requires some co-operation from the patient to place the nasal mask and breath effectively through the nose. ${ }^{2}$ In addition, there are reports of health issues and safety related to regular use. ${ }^{3}$ Considerable interest has been focused on the use of midazolam, a benzodiazepine, for oral sedation in young children. ${ }^{4-17}$

One of the difficulties with oral sedation is that once the bolus of benzodiazepine has been administered, the level of sedation cannot easily be altered. In the unlikely

\footnotetext{
${ }^{1 *}$ Associate Specialist in Paediatric Dental Sedation/ Honorary Clinical Teacher, ${ }^{2}$ Locum Consultant in Paediatric Dentistry/Honorary Professor, Department of Paediatric Dentistry, King's College Hospital, Camberwell, London, SE5 9RS

${ }^{*}$ Correspondence to: Liege Lourenço-Matharu Email: liege.matharu@kcl.ac.uk; Tel: +44 (0)2032993375
}

Online article number E12

Refereed Paper - accepted 17 June 2010

DOI: $10.1038 /$ sj.bdj.2010.886

${ }^{\circledR}$ British Dental Journal 2010; 209: E12 event of over-sedation, intravenous access is required to administer flumazenil. ${ }^{18}$

The report from the Standing Committee for Sedation for Dentistry classifies oral sedation for children under 12 years as an 'alternative technique. ${ }^{19}$ Competence in sedative techniques for children is recognised after successful completion of at least 100 cases. Practitioners in the United Kingdom must have four years of post-registration experience and training in paediatric cardio-pulmonary resuscitation. ${ }^{19}$

Oral sedation using midazolam has been used in the department of paediatric dentistry at King's College Hospital (KCH) since June 2007. It is an alternative to general anaesthesia for dental treatment in young children. Dental treatment and sedation were provided by only one dentist (LLM), who had formal sedation training. This included basic life support (BLS), paediatric basic life support (PBLS) and paediatric advanced life support (PALS).

\section{PATIENTS AND METHODS}

The sample comprised children referred to the paediatric sedation unit over the period from June 2007 to November 2009. Initial diagnosis and treatment planning was carried out at new patient clinics and casualty clinics in the department of paediatric dentistry at King's College Hospital. The options for pain control were explained and discussed with parent(s) or carers. These comprised behaviour management with/without local anaesthesia, behaviour management plus inhalation sedation with/without local anaesthesia, behaviour management plus oral sedation with/without local anaesthesia or general anaesthesia.

The following selection criteria were used:

1. Body weight less than $36 \mathrm{~kg}$

2. Children with clinical ratings of I, II or III using the American Society of Anaesthesiologists scale (ASA) ${ }^{20}$

3. Not allergic to benzodiazepines.

Once a decision had been made the parent/carer was provided with an information sheet, including the fact that midazolam is not licensed to be given orally. The weight of the child was taken and medical status confirmed. Parents were asked to give written consent for the treatment and sedation. It was explained that an adult escort was needed for each child when attending for treatment. Before treatment, medical status was revised, 


\begin{tabular}{|c|c|c|c|c|c|c|c|c|c|c|c|c|c|c|c|c|}
\hline & \multicolumn{4}{|c|}{ Age (Years) } & \multicolumn{3}{|c|}{ ASA } & \multicolumn{3}{|c|}{ Weight (kg) } & \multicolumn{3}{|c|}{ Dosage (mg) } & \multicolumn{3}{|c|}{ Ethnicity } \\
\hline & $\mathrm{N}$ & Mean & SD & Range & 1 & II & III & Mean & SD & Range & Mean & SD & Range & Caucasian & Black & Other \\
\hline Boys & 266 & 4.91 & 1.8 & $1.1-11.48$ & 247 & 14 & 5 & 19.9 & 4.8 & $8-36$ & 9.7 & 2.3 & 4-15 & 80 & 91 & 95 \\
\hline Girls & 244 & 5.15 & 1.9 & $1.2-11.05$ & 231 & 13 & 0 & 19.6 & 5.1 & $10-35$ & 9.7 & 2.4 & 5-15 & 79 & 78 & 104 \\
\hline
\end{tabular}

Table 2 Patients' movement and crying using Houpt Scale

\begin{tabular}{|l|l|l|l|l|l|l|l|l|}
\multicolumn{3}{c|}{} & \multicolumn{4}{c}{ Movement } & \multicolumn{3}{c}{ Crying } \\
\cline { 2 - 11 } & Violent & Continuous & Controllable & None & Hysterical & Continuous & Intermittent & None \\
\hline Boys & 5 & 33 & 59 & 169 & 9 & 31 & 60 & 166 \\
\hline Girls & 9 & 28 & 62 & 145 & 12 & 41 & 62 & 129 \\
\hline
\end{tabular}

the weight was checked and the time the child last ate was recorded. Parents were encouraged to take their children to empty their bladder to avoid children wetting themselves. The dose of midazolam was calculated by the formula of $0.5 \mathrm{mg} /$ $\mathrm{kg}$, although the maximum administered was $15 \mathrm{mg}$ in a single oral bolus. The ampoule's batch number, expiry date, dosage and time of administration were also recorded. The midazolam was given to the child by the operator-sedationist in the dental clinic either in a cup or syringe with flavoured sugar-free syrup. Patients were taken to a quiet room to play with toys, until they showed signs of being sedated. This was approximately $15 \mathrm{~min}$ utes, after which they were brought to the dental chair by their parents.

A pulse oximeter was attached to the child: this measured the peripheral arterial oxygenated haemoglobin saturation $\left(\mathrm{SpO}_{2}\right)$ and the heart rate. ${ }^{21}$ Visual monitoring of respiration and verbal contact were maintained throughout the treatment.

Treatment provided ranged from single procedures such as an extraction or filling to multiple procedures comprising multiple extractions and/or fillings, and preformed metal crowns.

The complexity of dental treatment was rated as simple, moderate, moderate to complex or complex. Simple treatment included extraction of single-rooted tooth or conservation without local anaesthetic (LA). Moderate included conservation of a permanent tooth using LA plus rubber dam, or extraction of a permanent multi-rooted tooth. Moderate to complex treatment was a mixture of conservation and extractions. Complex treatment included minor oral surgery.

Following completion of treatment, heart rate and $\mathrm{SpO}_{2}$ oxygen saturation were recorded. Each patient was discharged when alert and responsive. A leaflet giving postoperative instructions was provided.

The behaviour of the child during treatment was rated by the operator using the Houpt scale for level of sedation, movement, crying and overall behaviour. ${ }^{22}$

\section{Statistical tests}

All data subsets, for example boys and girls, were tested for normality using the Shapiro Wilk test. The Mann-Whitney U test was used for continuous variables and the Chi-Square or Fisher's Exact probability test for categorical variables. The statistical software used was Stata Release 9 (Stata Statistical Software, College Station, TX, USA).

\section{RESULTS}

A total of 515 young children were referred for treatment using oral sedation. The children were referred to the hospital by general dental practitioners $(313,61 \%)$, general practitioners or medical colleagues (10, 2\%), community services $(20,4 \%)$ and King's College Hospital casualty/emergency services (157, 31\%). Patients were assessed and referred for sedation by consultants $(\mathrm{n}=84$, $16.4 \%)$, associate specialists ( $\mathrm{n}=264,51.8 \%$ ) or postgraduate and undergraduate clinical trainees $(\mathrm{n}=162,31.8 \%)$.

Twenty-six patients (5\%) were reluctant to drink the midazolam syrup. With their parents help and permission, this was syringed into the patient's mouth while being gently held by the parent. Five children refused to drink the medicine, so the total number included in the analysis was 510 children.

The following patients' characteristics are shown in Table 1 . There were 266 boys and 244 girls. The mean ages were 4.9 years (range 11 months to 11.5 years) and 5.2 years (range 12 months to 11.0 years) for boys and girls respectively. The majority of patients were ASA I (478, 97\%), this included children with learning difficulties ( $n=20$ ) such as autism, Asperger's and Down's syndromes; achondroplasia $(n=2)$ and craniodystrophy $(\mathrm{n}=1)$; slightly overweight ( $\mathrm{n}=3$ ) and slightly underweight ( $\mathrm{n}=1)$. The ASA II group included children with sickle cell trait, hypothyroidism, rickets, cerebral palsy, controlled epilepsy, Wolfe Parkinson White syndrome and short oesophagus. In the ASA III group there were children with sickle cell disease, severe asthma, liver transplant, cardiac problems and uncontrolled epilepsy. All ASA III patients were in good health at the time of their sedation appointment and were checked for veins in case of the need for emergency cannulation. Supplemental oxygen was readily available.

There was no significant difference between girls and boys for the level of sedation: only two boys remained alert ( $p=0.500)$. No statistical differences were found for crying $(p=0.136)$ or movement ( $p=0.472$ ) (Table. 2).

The overall behaviour during dental treatment under sedation was recorded 


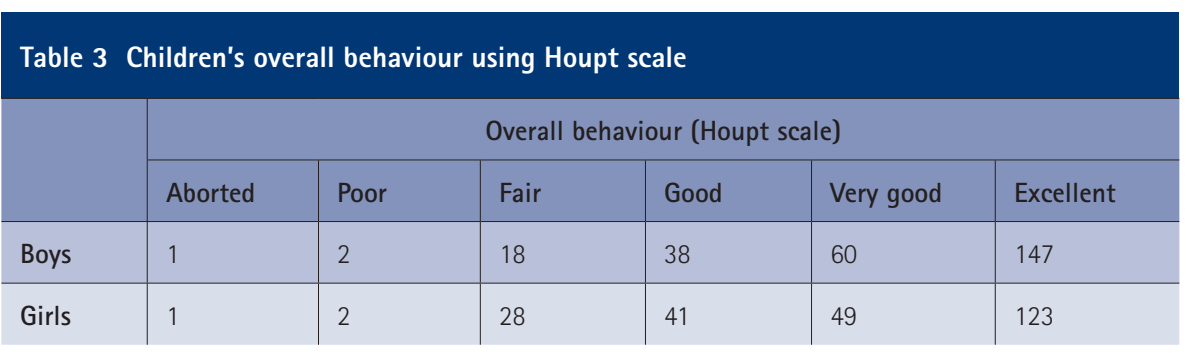

\section{Table 4 Complexity of treatment by gender}

\begin{tabular}{l|l|l|l|l|} 
& Simple & Moderate & Moderate to complex & Complex \\
\hline Boys & 116 & 115 & 30 & 5 \\
\hline Girls & 110 & 95 & 32 & 6 \\
\hline
\end{tabular}

$C h i^{2}=2.274 ; p=0.685 ;$ no significant difference between boys and girls

(Table 3). Good and very good scores reflected limited crying and movement. There were no significant differences regarding overall behaviour among boys and girls $(\mathrm{p}=0.450)$ (Table 3$)$.

One girl accepted the syrup but refused the treatment and was eventually treated using general anaesthesia (GA). One boy who discontinued treatment, one other boy and a girl only completed part of the treatment and were also treated under general anaesthesia. One further girl who was poorly behaved managed to complete the treatment. The 243 female children were included in the dental treatment rating analysis.

The complexity of treatment is shown in Table 4 and the treatments received are shown in Table 5. Twenty-four patients had a mixture of molar(s) and incisor(s) extractions which are not included in the tables. When complexity of treatment, weight and age were compared to the overall behaviour, no significant differences were found (Table 6).

Side-effects were present in 23\% of children $(\mathrm{n}=116)$. These included hiccups ( $\mathrm{n}=18$ ), crying/agitated in recovery ( $n=74)$, diplopia $(n=18)$ and lip biting ( $n=6)$. Patients who were scored 'fair', 'poor' or 'aborted' developed dysphoria during treatment. Other patients developed dysphoria after dental treatment was completed. Some patients became extremely upset when they were taken home after settling down in the recovery area. This was also considered dysphoria. Five very young patients passed water while sitting in recovery with their parents.

Arterial oxygen saturation was observed throughout dental treatment and recorded at the time of discharge. This was greater than 95\% for all children.

The time interval between the first hospital assessment and the treatment varied. One hundred and twelve children were treated within four weeks, a further 194 within 12 weeks. The remaining 127 received treatment within 13 to 24 weeks.

\begin{tabular}{|c|c|c|c|c|c|c|c|c|c|}
\hline & \multicolumn{3}{|c|}{ Restorative treatment } & \multirow{2}{*}{$\begin{array}{l}\text { Restorative plus } \\
\text { extractions }\end{array}$} & \multicolumn{4}{|c|}{ Extractions } & \multirow{2}{*}{$\begin{array}{l}\text { Surgical } \\
\text { Mucocele } \\
\text { frenectomy }\end{array}$} \\
\hline & No LA & Plus LA & $\begin{array}{l}\text { Stainless } \\
\text { steel crowns }\end{array}$ & & $\begin{array}{l}\text { Incisor } \\
\text { (single) }\end{array}$ & $\begin{array}{l}\text { Incisors - } \\
\text { (multiple: } 2 \text { to } 6 \text { teeth) }\end{array}$ & $\begin{array}{l}\text { Molar } \\
\text { (single) }\end{array}$ & $\begin{array}{l}\text { Molars (multiple: } \\
2 \text { to } 5 \text { teeth) }\end{array}$ & \\
\hline Boys & 8 & 8 & 17 & 37 & 60 & 72 & 39 & 71 & 3 \\
\hline Girls & 10 & 14 & 26 & 31 & 47 & 51 & 52 & 61 & 2 \\
\hline
\end{tabular}

Table 6 Comparison of behaviour versus dosage of midazolam using weight as surrogate, age and complexity of treatment

\begin{tabular}{|c|c|c|c|c|c|c|c|c|c|c|c|c|c|c|c|c|c|c|c|c|}
\hline \multirow[t]{3}{*}{ Behaviour } & \multicolumn{6}{|c|}{ Weight (kg) } & \multicolumn{6}{|c|}{ Age (yrs) } & \multicolumn{8}{|c|}{ Complexity of treatment } \\
\hline & \multicolumn{2}{|c|}{$<15$} & \multicolumn{2}{|c|}{15 to 30} & \multicolumn{2}{|c|}{$>30$} & \multicolumn{2}{|c|}{$<3$} & \multicolumn{2}{|c|}{3 to 6} & \multicolumn{2}{|c|}{$>6$} & \multicolumn{2}{|c|}{ Simple } & \multicolumn{2}{|c|}{ Moderate } & \multicolumn{2}{|c|}{$\begin{array}{l}\text { Moderate/ } \\
\text { complex }\end{array}$} & \multicolumn{2}{|c|}{ Complex } \\
\hline & B & G & B & G & B & G & B & G & B & G & B & G & B & G & B & G & B & G & B & G \\
\hline Aborted & 0 & 0 & 1 & 1 & 0 & 0 & 0 & 0 & 1 & 0 & 0 & 1 & 1 & 0 & 0 & 0 & 0 & 0 & 0 & 0 \\
\hline Poor & 0 & 0 & 2 & 3 & 0 & 0 & 0 & 0 & 1 & 1 & 1 & 2 & 2 & 2 & 2 & 0 & 1 & 1 & 0 & 0 \\
\hline Fair & 2 & 5 & 15 & 21 & 1 & 2 & 3 & 4 & 12 & 16 & 3 & 8 & 22 & 17 & 18 & 8 & 4 & 1 & 2 & 2 \\
\hline Good & 4 & 9 & 33 & 31 & 1 & 0 & 7 & 9 & 20 & 20 & 11 & 11 & 23 & 13 & 34 & 15 & 18 & 10 & 3 & 2 \\
\hline Very Good & 2 & 5 & 54 & 41 & 4 & 3 & 7 & 5 & 33 & 27 & 20 & 17 & 53 & 23 & 43 & 18 & 12 & 8 & 1 & 0 \\
\hline Excellent & 13 & 16 & 126 & 100 & 8 & 7 & 18 & 15 & 102 & 75 & 27 & 33 & 125 & 55 & 113 & 54 & 27 & 12 & 5 & 2 \\
\hline $\begin{array}{l}\mathrm{B}=\text { boys, } \mathrm{G}=\mathrm{g} \\
\mathrm{Complexity} \mathrm{t} \mathrm{t} \\
\mathrm{Ch}^{2}=19.7955 \\
\mathrm{Ch}^{2}=15.5101 ; \\
\text { Weight and ber } \\
\mathrm{Ch}^{2}=6.5549 ; \\
\mathrm{Ch}^{2}=3.6250 ;\end{array}$ & $\begin{array}{l}=0.415 \\
\text { viour: } \\
\text { ve }\end{array}$ & . & differs & hen & & & & & & & & & & & & & & & & \\
\hline
\end{tabular}




\section{DISCUSSION}

The use of sedation for dental treatment in young children has attracted considerable interest since the publication of the government paper 'A conscious decision. ${ }^{19}$ A major consequence of this was the change in the arrangements for general anaesthesia (GA) for dentistry. This has led to a welcome shift in service provision from GA to sedation. In addition, the sedation for use by the operator-sedationist is now widely referred to as conscious sedation. ${ }^{23}$ This falls within the current government guidelines highlighting the importance of reducing the use of GA. ${ }^{19}$ However, the technique of inhalation sedation is not successful for children who cannot use the nasal mask correctly. This is because the technique requires some co-operation from the patient.

A recent systematic review included some studies carried out in different countries using midazolam as the oral sedative for children, ${ }^{24}$ but little work has been carried out in the UK to assess the use of oral midazolam in children. For this reason it was decided to evaluate midazolam administered orally to determine its efficacy in the delivery of dental care to unco-operative or very small children. Apart from the physical sedative effect, midazolam is well known for its amnesic effect. This is important as the distress experienced by some children is not remembered.

Perusal of the literature indicated that a dose of $0.5 \mathrm{mg} / \mathrm{kg}$ body weight is likely to give good results. The potential for oversedation and the consequent risk to the child required that a carefully prescribed sedation regimen was followed. The maximum recommended dosage of oral midazolam should not exceed $20 \mathrm{mg},{ }^{25}$ so to provide a wide safety margin the maximum dose was set at $15 \mathrm{mg}$, which corresponds to $30 \mathrm{~kg}$. A small number of children heavier than $30 \mathrm{~kg}$ were accepted for treatment, for example an anxious, eleven-year-old girl weighing $36 \mathrm{~kg}$ with achondroplasia, who received $15 \mathrm{mg}$ of oral midazolam.

Parents were encouraged to be present to support their own child, but it was occasionally necessary to reassure parents while carrying out treatment. Their presence had infrequent benefits when a child was, despite the sedation, disruptive so the parent(s) used gentle clinical holding techniques to facilitate care and allow treatment to be completed. Before continuing with treatment the parents were offered the option of abandoning treatment and the remaining care to be rescheduled for treatment using general anaesthesia.

One important pre-requisite of midazolam sedation is that the operatorsedationist must be capable of placing an intravenous cannula to enable the prompt administration of the reversal drug, flumazenil. These enhanced skills also extend to competence in providing paediatric life support. This effectively limits oral sedation by an operator-sedationist to conscious sedation specialist centres. This may appear to be overcautious but parents can reasonably expect that if an emergency occurs, full and adequate life support will be immediately available.

Only one child required sedation reversal with flumazenil $500 \mu \mathrm{g}$ as he appeared to be over-sedated by sleeping deeply. The mother explained that the child had not slept well for three days and nights because of an ear infection. This suggests that the child, once treatment was completed fell asleep helped by the still circulating midazolam.

Arterial oxygen saturation only dropped due to sudden movement or accidental removal of the soft clip by the child. Otherwise this remained above 95\% at all times.

The establishment of the oral sedation clinics at $\mathrm{KCH}$ has resulted in children with infection or in pain receiving treatment within a few weeks. Without sedation these children would have had to wait for many months for general anaesthesia. As reported, 52 (10\%) were seen on the same day, 60 (11.76\%) within a week, and 87 (17\%) within four weeks. Most of the other children were seen at longer intervals largely because of their family arrangements or because treatment using local anaesthesia had been attempted before referral for oral sedation. Although the general tenet is to provide only small amounts of treatment it has been possible to extract or restore up to six teeth in a single sedation appointment.

The reluctance of some children to drink the medicated syrup is a limitation of this technique, due to its bitter taste or their young age.
Not all children were still or quiet, and occasionally the procedure was completed with difficulty. An audit is being carried out assessing parents' satisfaction and their perception of the child's memory of the treatment, in addition to any late sideeffects. Few parents reported that the child was upset by the drowsiness or a numb lip. The worst memory was of the bitter tasting midazolam. Some parents also reported that it was unpleasant seeing the child distressed during treatment even though they knew the child would have very little recollection of events.

\section{CONCLUSION}

Midazolam sedation was well tolerated and accepted by parents and children. Most of the children (379, 74\%) exhibited 'very good' to 'excellent' overall behaviour during treatment. Some of the children who became upset during dental treatment settled down happily soon afterwards. A group of children became tearful or upset while in recovery due to the numbness of the lip and required a lot of distraction to take their mind of it. Others were happily playing in the recovery area, but became inconsolable when their parents took them home.

For children reluctant to drink the syrup, with parent's permission and gentle holding, the oral midazolam may be syringed into the back of the mouth. This initiates the swallowing reflex.

The safety of midazolam was confirmed as no decrease in oxygen levels was experienced. As a side-effect, diplopia was noted only when patients mentioned seeing 'two mummies' or 'my daddy has four eyes'. Diplopia may be more common than reported in this study. The most common side-effect after sedation was becoming upset about the numbness or feeling drowsy and unable to walk or run.

Sedating children is difficult, but oral midazolam enables dental treatment to be carried out efficiently. This preliminary case series study has demonstrated the value of oral midazolam in clinical practice. Further double-blind randomized controlled trials are needed to determine the most effective dose that enables treatment to be carried out with minimum undesirable effects.

The authors would like to thank Victoria Lucas for her assistance with the text. 
1. Hosey M T. Managing anxious children: the use of conscious sedation in paediatric dentistry. Int $J$ Paediatr Dent 2009; 12: 359-372.

2. Holroyd I, Roberts G J. Inhalation sedation with nitrous oxide: a review. Dent Update 2000; 27: 141-146.

3. Yagiela J A. Health hazards and nitrous oxide: a time for reappraisal. Anesth Prog 1991; 38: 1-11.

4. Gallardo F, Cornejo G, Borie R. Oral midazolam as premedication for the apprehensive child before dental treatment. J Clin Pediatr Dent 1994; 18: 123-127.

5. Haas D A, Nenniger S A, Yacobi R, Magathan J G, Grad H, Copp P E. A pilot study of the efficacy of oral midazolam for sedation in pediatric dental patients. Anesth Prog 1996; 43: 1-8.

6. Lima A R A, Costa LR R S, Costa PS S. A randomized controlled crossover trial of oral midazolam and hydroxyzine for pediatric dental sedation. Pesqui Odontol Bras 2003; 17: 206-211.

7. Downs T, Dembo J, Lyons T D, Pelphery A. A comparative study of midazolam to meperidine/ promethazine as an IM sedative technique for the pediatric dental patient. ASDC J Dent Child 1997; 64: 197-200.

8. Hartgraves P M, Primosch R. An evaluation of oral and nasal midazolam for pediatric dental sedation. ASDC J Dent Child 1994; 61: 175-181.

9. Marshall W R, Weaver B D, McCutcheon P. A study of the effectiveness of oral midazolam as a dental pre-operative sedative and hypnotic. Spec Care Dentist 1999; 19: 259-266.

10. Musial K M, Wilson S, Preisch J, Weaver J. Comparison of the efficacy of oral midazolam alone versus midazolam and meperidine in the pediatric dental patient. Pediatr Dent 2003; 25: 468-474.

11. Roelofse J A, Joubert J J, Roelofse P G. A double-blind randomized comparison of midazolam alone and midazolam combined with ketamine for sedation of pediatric dental patients. J Oral Maxillofac Surg 1996; 54: 838-844.

12. Shapira J, Kupietzky A, Kadari A, Fuks A B, Holan G. Comparison of oral midazolam with and without hydroxyzine in the sedation of pediatric dental patients. Pediatr Dent 2004; 26: 492-496.

13. Singh N, Pandey R K, Paksena A K, Aiswal J N. A comparative evaluation of oral midazolam with other sedatives as premedication in pediatric dentistry. J Clin Pediatr Dent 2002; 26: 161-164.

14. Wilson KE, Welbury R R, Girdler N M. A randomised, controlled, crossover trial of oral midazolam and nitrous oxide for paediatric dental sedation. Anaesthesia 2002; 57: 860-867.

15. Wilson K E, Girdler N M, Welbury R R. A comparison of oral midazolam and nitrous oxide sedation for dental extractions in children. Anaesthesia 2006; 61: 1144.

16. Aydintug $Y S, O k c u$ K M, Guner $Y$, Gunaydin $Y$, Sencimen M. Evaluation of oral or rectal midazolam as conscious sedation for pediatric patients in oral surgery. Mil Med 2004: 169: $270-273$.

17. Lee-Kim S J, Fadavi S, Punwani I, Koerber A. Nasal versus oral midazolam sedation for pediatric dental patients. J Dent Child (Chic) 2004; 71: 126-130.

18. Craig D, Skelly M. Practical conscious sedation. pp 86. London: Quintessence Publishing, 2004.

19. Avery B S, Hulf J. Standards for conscious sedation in dentistry: alternative techniques. pp 1-31. London: Royal College of Anaesthetists and the Royal College of Surgeons of England, 2007.

20. ASA. ASA classification. New classification of physical status. Anaesthesiology 1963; 24: 111.

21. Payne J P, Severinghaus J W. Pulse oximetry. Berlin: Springer-Verlag, 1986.

22. Houpt M I, Kupietzky A, Tofsky N, Koenigsberg S. Effects of nitrous oxide on diazepam sedation of young children. Pediatr Dent 1996; 18: 236-241.

23. Department of Health. A conscious decision. A review of the use of conscious sedation and general anaesthesia in primary dental care. London: Department of Health, 2000.

24. Matharu L L, Ashley P F. What is the evidence for paediatric dental sedation? J Dent 2007; 35: 2-20.

25. Yasny J S, Asgari A. Consideration for the use of enteral sedation in pediatric dentistry. J Clin Pediatr Dent 2008; 32: 85-93. 